\title{
A note on policy capturing as a method for studying social desirability
}

\author{
ANTHONY L. ROSSI, JR. \\ State University of New York at Albany, Albany, New York \\ and \\ JOSEPH M. MADDEN \\ Rensselaer Polytechnic Institute, Troy, New York
}

\begin{abstract}
Policy capturing was used to identify and quantify subjects' use not only of relevant factors but of socially desirable factors as well. The technique revealed how a subject weighted a socially undesirable factor in a manner which he/she was either not willing or not able to convey in a more direct ranking procedure. Not only did policy capturing allow us to identify reliance on such a factor in terms of a significant beta weight, it also gave us an estimate of its relative contribution to the individual's decision-making strategy.
\end{abstract}

The tendency for an individual to respond on an inventory or questionnaire so as to be portrayed in a desirable manner is a well-documented phenomenon (Edwards, 1957; Smith, 1975). Although the tendency to describe oneself in desirable terms may contribute in some instances to the validity of the instrument (i.e., self-esteem measurement), responses reflecting "social desirability" most frequently are unwelcome in the data-gathering situation. Nunnally (1967) suggested that responses reflecting social desirability may be the result mainly of response styles and/or individual differences in the tendency to "fake good." Because both of these sources of reactive response are usually unrelated to the purpose of the instrument, they tend to contaminate any data obtained, rendering tenuous subsequent interpretations. In discussing the sources of social desirability, Nunnally states:

There is enough circumstantial evidence to show that ... a large share of its (social desirability) variance concerns ... traits such as self-knowledge and frankness. Unfortunately, we do not know how to measure these components separately...(p. 481)

The basic problem in dealing with social desirability lies in the very detection of its occurrence. The investigator often is not sure when it is present and, even in rare instances when it does appear to be operating, it is difficult to estimate its magnitude. The purpose of this paper is to show how a policy-capturing technique might be used to deal with this problem.

Address correspondence to: Joseph M. Madden, Department of Psychology, Rensselaer Polytechnic Institute, Troy, NY 12180-3590.

\section{METHOD}

\section{Subjects}

The subjects were 15 undergraduate volunteers majoring in psychology.

\section{Instrument}

Profiles of hypothetical college students were formed by generating a factorial arrangement of five dichotomized factors. These factors were reasons a student might use in deciding whether or not to take a certain course: interest in psychology, fulfillment of degree requirements, worthwhile learning experience, easy grade, and friends in the course. In each hypothetical student profile, a high or low level of influence exerted in the decision to take a course was indicated for each of the five factors. Five factors dichotomized in this manner yield 32 combinations or profiles. One of the profiles is given in Figure 1.

The rationale for choosing these specific factors lies in the degree to which each seems to lend itself to simulating socially desirable responses. Whereas the first three factors are likely to be recognized by students as socially acceptable reasons for taking a course, the "easy grade" and "friends in course" factors are more likely to be seen as socially undesirable.

\section{Tasks}

Policy-capturing task. The subjects were informed that the profiles indicated the extent to which each of the five factors influenced, to a high or low degree, 32 students' decisions to take a course. The subjects used a 5-point scale to indicate the extent to which the course-taking

Factor Levels of Influence

\begin{tabular}{ll}
\hline 1. Interest in psychology & High \\
2. To fulfill degree requirements & Low \\
3. As a worthwhile learning experience & Low \\
4. To get an easy grade & High \\
5. My friends are in this course & Low \\
\hline
\end{tabular}

Figure 1. An example of a profile consisting of the five factors and the degree of influence exerted (high or low) in the decision to take a course. 
Table 1

Results of the Point-Distribution Task for Groups Assigning or Not Assigning Points to the "Easy Grade" Factor

\begin{tabular}{lcc}
\hline & $\begin{array}{c}\text { No Points } \\
\text { Group }\end{array}$ & $\begin{array}{c}\text { Points } \\
\text { Group }\end{array}$ \\
\hline Interest in psychology & 27.4 & 37.9 \\
Learning experience & 31.0 & 26.2 \\
Fulfillment of requirements & 40.0 & 18.3 \\
Easy grade & 0.0 & 16.7 \\
Friends in course & 1.6 & .9 \\
\hline
\end{tabular}

Note-For each group, $N=6$. Percents are used because the total of . the means does not add up to 100 since the total number of points assigned by some subjects did not equal 100.

policy of each student profile was similar to that of the subject, with 5 indicating "very similar" and 1 indicating "not at all similar."

Point-distribution task. The subjects were also asked to distribute 100 points among the five factors indicating each factor's relative importance in their own decision to take a course.

\section{Analysis}

The subjects were split into two groups. One group consisted of those subjects who indicated that an easy grade was not an important reason for taking a course by not distributing any points to the "easy grade" factor; the other group consisted of those subjects who admitted that this factor influenced their course-taking decision by allocating at least 10 points to this factor. Data from 3 subjects were eliminated from the analysis because they allocated more than 0 but less than 10 points to the "easy grade" factor. A second grouping variable, based on subjects' differential allocation of points to the other socially undesirable factor, "friends in course," was precluded when only 2 subjects were found to have allocated points (both less than 10) to this factor.

In order to examine each subject's course-selection policy with respect to the five factors, a squared multiple correlation $\left(R^{2}\right)$ was obtained by regressing with subject's response on the five factors, with "easy grade" being omitted from the equation. Thus, the increment in $\mathbf{R}^{2}$ added to the other four factors was generated for the "easy grade" variable. The .05 probability level was used in conjunction with a stepwise solution.

\section{RESULTS}

The results of the point-distribution task can be found in Table 1. Two distributions of points, one for those 6 subjects who assigned points to the "easy grade" factor and one for the 6 subjects who did not assign points to this factor, are presented.

Table 2

Total $\mathbf{R}^{2}, \mathbf{R}^{2}$ Increment for "Easy Grade," Sign of Beta Statistic, and Incremental $F$ Ratio for Subjects Distributing Points to "Easy Grade"

\begin{tabular}{ccccc}
\hline Subject & $\begin{array}{c}\mathbf{R}^{2} \\
\text { Total }\end{array}$ & $\begin{array}{c}\mathbf{R}^{2} \text { Increment } \\
\text { Easy Grade }\end{array}$ & $\begin{array}{c}\text { Beta } \\
\text { Sign }\end{array}$ & $\begin{array}{c}\text { Incremental } \\
\text { F Ratio }\end{array}$ \\
\hline 1 & .87 & .12 & Pos & $24.9^{*}$ \\
2 & .81 & .13 & Pos & $18.5^{*}$ \\
3 & .89 & .01 & Pos & 2.5 \\
4 & .86 & .01 & Pos & 1.9 \\
5 & .88 & .14 & Pos & $31.5^{*}$ \\
6 & .83 & .03 & Pos & $4.7 \dagger$ \\
\hline
\end{tabular}

${ }^{*} p<.01 . \quad \dagger p<.05$
Table 3

Total $\mathbf{R}^{2}, \mathbf{R}^{2}$ Increment for "Easy Grade," Sign of Beta Statistic, and Incremental F Ratio for Subjects Distributing No Points to "Easy Grade"

\begin{tabular}{ccccc}
\hline Subject & $\begin{array}{c}\mathrm{R}^{2} \\
\text { Total }\end{array}$ & $\begin{array}{c}\mathrm{R}^{2} \text { Increment } \\
\text { Easy Grade }\end{array}$ & $\begin{array}{c}\text { Beta } \\
\text { Sign }\end{array}$ & $\begin{array}{c}\text { Incremental } \\
\text { F Ratio }\end{array}$ \\
\hline 7 & .81 & .31 & $\mathrm{Neg}$ & $44.0^{*}$ \\
8 & .75 & .04 & $\mathrm{Neg}$ & $4.3 \dagger$ \\
9 & .86 & .03 & $\mathrm{Neg}$ & $5.8 \dagger$ \\
10 & .89 & .02 & $\mathrm{Neg}$ & $4.9 \dagger$ \\
11 & .56 & .14 & Pos & $8.6^{*}$ \\
12 & .56 & .01 & $\mathrm{Neg}$ & $<1.0$ \\
\hline
\end{tabular}

${ }^{*} p<.01 . \quad+p<.05$.

The results of the incremental F test for "easy grade" in each subject's equation are presented in Tables 2 and 3 . As expected, all of the subjects who distributed points to "easy grade" (Table 2) produced positive betas for this factor, of which four were significant at the .05 level. This suggests that hypothetical profiles containing this factor appeared more similar to their own than did profiles not containing this factor.

Table 3 shows that 5 of the 6 subjects who did not distribute points to the "easy grade" factor produced negative beta weights, indicating that they saw this factor as a significant negative influence. For one subject, the direction of the beta weight on this factor was positive and contrary to what was reported during the point-distribution task, suggesting that this subject was indeed influenced by the "easy grade" factor in a manner quite different from what he was willing to admit.

\section{DISCUSSION}

These findings illustrate how the elegant descriptive capacity of the policy-capturing technique enables the researcher to identify and quantify subjects' use not only of relevant factors but of social desirability factors as well. The technique revealed how a subject weighted a socially undesirable factor in a manner which he/she was either not willing or not able to convey in a more direct ranking procedure. Not only did policy capturing allow us to identify reliance on such a factor in terms of a significant beta weight, it also gave us an estimate of its relative contribution to the individual's decision-making strategy.

Clearly, the subtle, indirect nature of the policy-capturing technique suggests its potential for application in a wide variety of situations where more direct means of attitude or interest measurement are subject to social desirability effects.

\section{REFERENCES}

EDWARDS, A. L. (1957). The social desirability variable in personality assessment and research. New York: Holt.

Nunally, J. C. (1967). Psychometric theory. New York: McGraw-Hill. SмIтн, H. W.(1975). Strategies of social research: The methodological imagination. Englewood Cliffs, NJ: Prentice-Hall.

(Manuscript received for publication June 15, 1985.) 